\title{
Digital Differential Current Protection Scheme of Transformer Using an Arduino UNO Microcontroller
}

\author{
Emmanuel Ighodalo Okhueleigbe*, Joseph Ailenokhuoria Ogbekhiule \\ Department of Electrical and Electronics Engineering, Federal University of Petroleum Resources (FUPRE), Effurun, Delta State, Nigeria \\ Email address: \\ okhueleigbe.emmanuel@fupre.edu.ng (E. I. Okhueleigbe), ogbekhiule.joseph@fupre.edu.ng (J. A. Ogbekhiule) \\ ${ }^{*}$ Corresponding author
}

To cite this article:

Emmanuel Ighodalo Okhueleigbe, Joseph Ailenokhuoria Ogbekhiule. Digital Differential Current Protection Scheme of Transformer Using an Arduino UNO Microcontroller. International Journal on Data Science and Technology. Vol. 5, No. 1, 2019, pp. 35-39.

doi: $10.11648 /$ j.ijdst.20190501.15

Received: February 28, 2019; Accepted: April 17, 2019; Published: June 3, 2019

\begin{abstract}
Transformers are the key equipment in electrical power transmission. So the use of transformers protection in electric power systems is very crucial and critical as they are required for efficient transportation of electricity to consumers for long term. This paper is concerned with the differential current protection scheme of transformer using a differential relay technique with arduino Uno microcontroller as a differential relay responsible for comparing the differential current values and sends trip signal to the relay (acting as circuit breaker) to open the circuit when there is fault in the protected zone as a result of imbalance in the differential current values. The system is efficient in transformer protection, gives better isolation, has accurate fault detection and quick response time to clearing faults
\end{abstract}

Keywords: Transformers, Differential Current Protection, Arduino Uno Microcontroller, Relays, Current Transformers

\section{Introduction}

The demand of electricity in our modern day as led to advancement in electrical power systems, which is reflected in the development of all the power system device generators, different sizes of transformers, transmission lines and the protection equipment. In A. C transmission, power transformer is one of the most important equipment. It is expensive uninterrupted and desired to be kept in good condition always to have supply.

Due to advancement in technology and daily use of electrical devices by industries, organizations and individuals, there is an increase in electricity demand which most likely results systems overload, reducing its efficiency and can cause damage to the transformer [1].

Typically, Power systems are built to allow continuous generation, transmission and consumption of energy. The system is capable of sustaining a variety of environmental and operating impacts that resemble normal operating conditions which may include lightning striking the transmission lines, excessive loading, deterioration or breakdown of the equipment insulation resulting to power systems experiencing occasional faults such as phase to phase or phase to ground faults, over current, over voltage or even temperature based faults. These faults, as in the case of phase to phase or phase ground faults could cause an imbalance of phase current (i.e. differential current) and can be prevented using differential protection and microcontroller based relay protection.

The Differential current protection scheme is based on the principle that the input power to the transformer under normal condition is equal to the output power and is concerned with having a differential or balanced current between the primary and secondary side which would be digitally displayed [2]. The protective relay techniques provide accurate reproduction of normal and abnormal conditions for correct sensing and operation.

Different methods have being suggested by the researchers and are adopted in implementing a differential protection scheme for power transformer which is microcontroller based, [3] designed a differential current protection of singlephase transformer using Arduino with voice alert. The protection techniques employed differential relay mechanism with Arduino. At all times, the Arduino senses the condition of the transformer. If it finds any error then it sends 
commands to the circuit breakers to trip the main potential transformer and the buzzer gives an alert.

[4] Ochieng designed a microcontroller based power transformer protection system which uses a current sensor as the interfacing instrument between the current transformer and the pic16f690 microcontroller. The current sensor acs $712 \mathrm{x}$ series was used in the project as the interfacing instrument between the power transformer and the pic16f690 microcontroller.

This paper is concern with the implementation of digital differential current protection of a single phase transformer using Arduino Uno microcontroller as a mechanism of differential relay. A power transformer functions as a node to connect two different voltage levels [3]. The fundamental idea of the differential current protection scheme is to provide protection to the transformer if any fault occurs in the protected zone that will cause an imbalance in the differential currents. The output power in a transformer is equal to that of the input power hence, for differential current protection of the current transformers reduces the currents at the primary and secondary sides to a measureable value and in such a way that they are equal [5]. When there is an occurrence of internal fault an imbalanced or non-zero differential current will flow through the operating coil of the differential relay which would be substituted with a microcontroller that sends a trip signal to the relays needed to open the circuit. The differential protection scheme is concerned with the faults that arise from associated difficulties such as the magnetizing inrush current and saturation. The magnetizing inrush current is a phenomenon that occurs during brief initial state of energization of the transformer even when the secondary side has no load connected to it and has its current a lot higher than the rated current [6-8]. It is transient in nature so it lasts for just a few seconds and does not cause any permanent damage to the transformer.

\section{Components Used}

Some of the major components needed are listed below:

Power transformer

Current transformer

Current sensors

Arduino Uno microcontroller

LCD 20x4

Voltage sensor

Variac

Loads: 60Wx2, 100W

Relays

Voltage regulator

Bridge rectifier

\section{Work Principle}

The power transformer to be protected is connected to the main AC supply and delivered power $(\mathrm{P}=\mathrm{IV})$ to the output terminal. The power transformer primary and secondary currents are measured by the current transformers, which are to be protected by the Arduino and the circuit breaker. The step-down transformer is used to step down the primary or source voltage from 220 to $12 \mathrm{~V}$. This $12 \mathrm{~V}$ is regulated to $5 \mathrm{~V}$ (using $\mathrm{L} 7805 \mathrm{CV}$ voltage regulator) which is the required voltage for the Arduino. The current transformers are each connected to the primary and secondary side of the step-up transformer and are used to reduce the currents to a measureable value that can be sensed by the current sensors.

The Arduino microcontroller acts as differential current comparator connected to both current sensors ACS712 and as control unit in this design. As a differential current comparator it is used to compare the current values from the outputs of both Current sensors at the primary and secondary sides of the power respectively, computes their resultant difference, which would process an instruction to send a trip signal to the relay depending on its programming and the time required to clear a fault. Acting as a control unit, used for monitoring and controlling the working activities of the protection zone and display values of voltage and currents sensed by the voltage sensor and current transformers respectively.

A bridge rectifier is used to convert the alternating current from the secondary side of the step-down transformer to direct current for use by the microcontroller. The current are first connected in series and then in parallel to the secondary side of the step-up transformer to display. Variac is introduced in the system to vary and show the characteristics of the differential protection scheme when differential current is below zero and above zero respectively. The LCD display is used to display the differential current values of the transformer and to display the voltage and current level of the system as well.

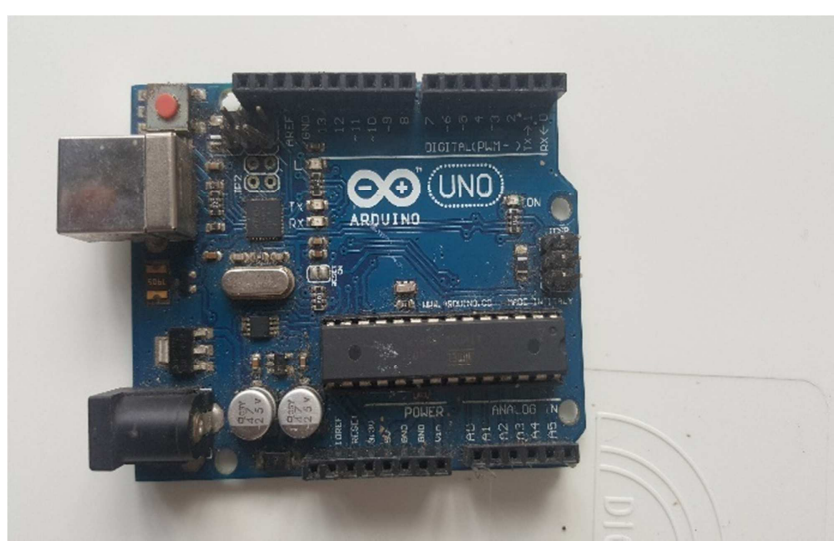

Figure 1. Arduino Uno Board. 


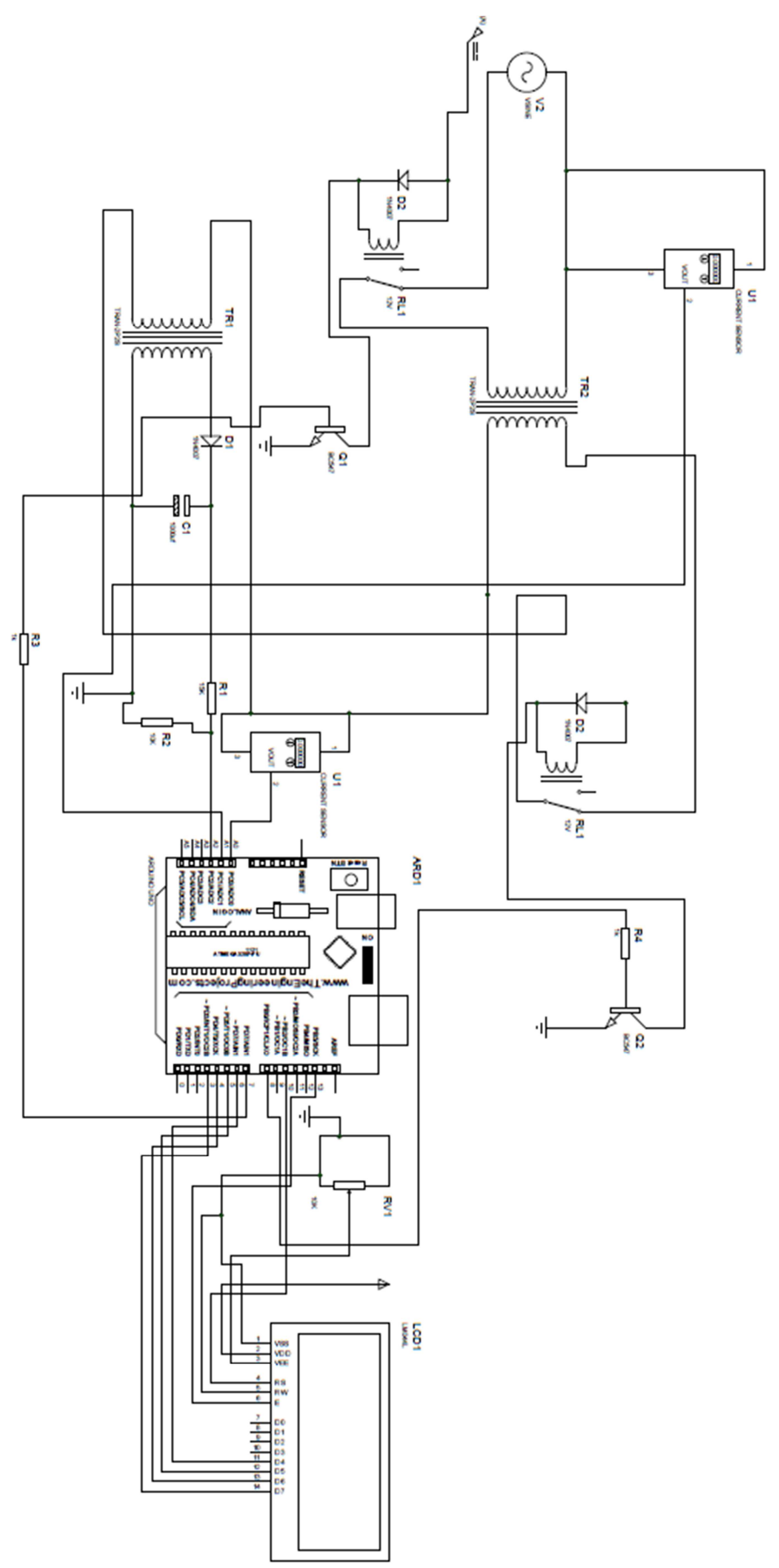

Figure 2. Proteus Simulation of the Protection Scheme. 


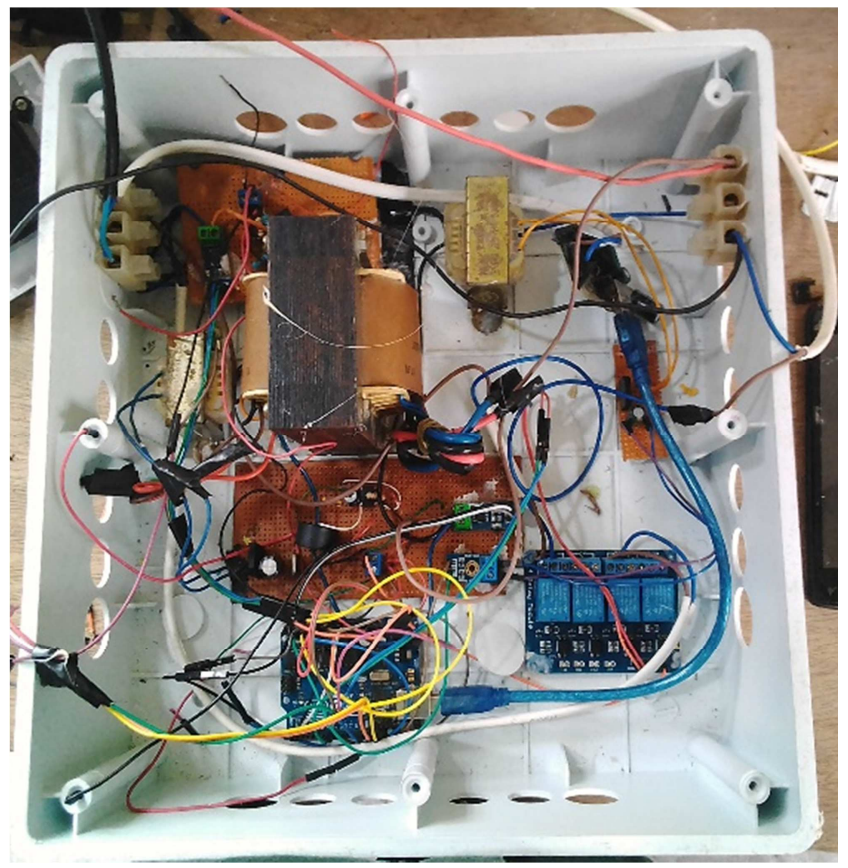

Figure 3. Hardware.

The flow chart above is a brief description of how the differential protection scheme works using arduino microcontroller as the differential relay.

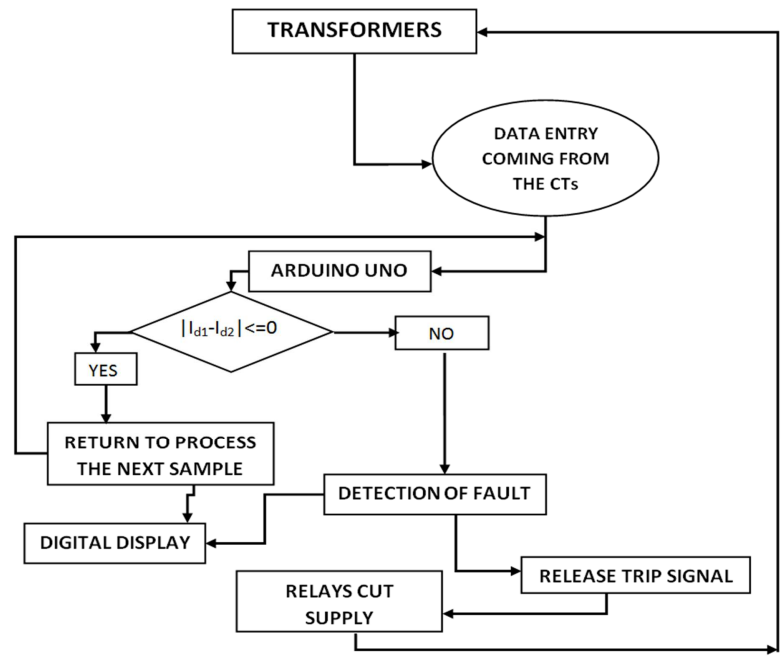

Figure 4. Flow chart representation of the differential current protection working principle.

\section{Results and Discussion}

The differential protection of a transformer is implemented using Arduino Uno microcontroller as a decision making device that sends a trip signal to the relay (acting as circuit breaker) whenever there is faults (internal or external faults). The state of the system was divided into No load, faulty and normal conditions and were displayed on the $20 * 4$ LCD display with a delay of 3 seconds as programmed on the arduino.

The following table shows the result from the conditions of the system

Table 1. Result values from the Normal test condition.

\begin{tabular}{lllll}
\hline LOAD CONNECTED & PRIMARY CURRENT & SECCONDARY CURRENT & CURRENT DIFFERENCE & REMARK \\
\hline $260 \mathrm{~W}$ & $0.72 \mathrm{~A}$ & $0.54 \mathrm{~A}$ & $0.18 \mathrm{~A}$ & NO TRIP \\
$200 \mathrm{~W}$ & $0.55 \mathrm{~A}$ & $0.39 \mathrm{~A}$ & $0.16 \mathrm{~A}$ & NO TRIP \\
$60 \mathrm{~W}$ & $0.34 \mathrm{~A}$ & $0.18 \mathrm{~A}$ & $0.16 \mathrm{~A}$ & NO TRIP \\
\hline
\end{tabular}

Table. 2. Result values from the Faulty test condition.

\begin{tabular}{lllll}
\hline LOAD CONNECTED & PRIMARY CURRENT & SECCONDARY CURRENT & CURRENT DIFFERENCE & REMARK \\
\hline $260 \mathrm{~W}$ & $0.93 \mathrm{~A}$ & $0.59 \mathrm{~A}$ & $0.34 \mathrm{~A}$ & TRIP \\
$200 \mathrm{~W}$ & $0.71 \mathrm{~A}$ & $0.47 \mathrm{~A}$ & $0.24 \mathrm{~A}$ & TRIP \\
$60 \mathrm{~W}$ & $0.43 \mathrm{~A}$ & $0.21 \mathrm{~A}$ & $0.22 \mathrm{~A}$ & TRIP \\
\hline
\end{tabular}

Table. 3. Result values from NO LOAD test condition.

\begin{tabular}{lllll}
\hline LOAD CONNECTED & PRIMARY CURRENT & SECCONDARY CURRENT & CURRENT DIFFERENCE & REMARK \\
\hline NO LOAD & $0.37 \mathrm{~A}$ & $0.06 \mathrm{~A}$ & $0.31 \mathrm{~A}$ & NO TRIP \\
\hline
\end{tabular}

From the test carried out, it was observed that the current values gotten from the primary and secondary side of the system in Faulty conditions were larger than that gotten in Normal conditions and also the current difference were also larger for Faulty than Normal condition. For the load with both the $200 \mathrm{~W}$ and $60 \mathrm{~W}$ bulbs the current values and difference were larger than with each connected separately. At No load the secondary current is very close to zero as a result of open circuit at the secondary.

\section{Conclusion}

This paper seeks to design an alternative method of transformer protection with a digitally displayed, Arduino based system that will intelligently monitor faults which may arise due to current imbalance of the transformer and prompts a safety measure to protect the transformer. From the results gotten it can be seen that the microcontroller based relay is initiated by the Arduino only when the system is in 
its faulty state. The microcontroller based relay is a technological advancement or development as compared to the use of conventional relays which improves the efficiency and reliability of the system which could be beneficial to both the society and its economic growth.

\section{References}

[1] K. Salunke, S. Sheikh, S. B Kunure (2016). "Transformer protection using microcontroller based relay and monitoring using GSM technology" International engineering research journal (IERJ), Vol. 2 issue 2, page 813-817, 2016, ISSN 2395 $-1621$.

[2] Adel, A. \& Rahman, M. A. (2011). "A Software Design Technique for Differential Protection of Transformers", International Electric Machines \& Drives Conference (IEMDC), IEEE.

[3] Sarfaraz, N. S., Radica S. \& Sandy M. N. R. (2015). "Digital Protection of Transformer using Arduino with Voice Alert", International Journal of Innovations in Engineering and Technology (IJIET), Vol. 6, Issue 2.

[4] Ochieng', A. O. (2015). "Microcontroller based power transformer protection".

[5] S. M. Bashi, N. Marium and Rafa (2007). "Power Transformer Protection using Microcvontroller Based Relay.", Journal of Applied Science 7 (12): 1602-1607, 2007. ISSN 1812-5654.

[6] Electric4u.com. (2018, August 27). https: //www.electrical4u.com/magnetizing-inrush-current-in-powertransformer/. Retrieved from www.electric4u.com: https: //www.electrical4u.com/magnetizing-inrush-current-in-powertransformer/.

[7] P. Afzal, P. Jigar, T. Raj, K. Abhishek, K Bariya. (2017). "Differential Current Protection of Transformer Using Arduino with Voice Alert" International Journal of Advance
Engineering and Research Development (IJARED), P-ISSN; 2348-6406.

[8] V. Kumar, k. Vivek, V. Verma, (2015) "A Microcontroller Based Online Fault Detection System” IJEE, VOL 7 page 1-4, 2015, ISSN 0973-7383.

[9] S. M. Bashi (2007). "Power Transformer Protection using Microcvontroller Based Relay.", Journal of Applied Science 7 (12): 1602-1607, 2007. ISSN 1812-5654.

[10] V. Kumar (2015) "A Microcontroller Based Online Fault Detection System" IJEE, VOL 7 page 1-4, 2015, ISSN 0973 7383.

[11] Adel, A. (2011). "A Software Design Technique for Differential Protection of Transformers", International Electric Machines \& Drives Conference (IEMDC), IEEE.

[12] P. Afzal, P. Jigar, T. Raj, K. Abhishek, K Bariya. (2017). "Differential Current Protection of Transformer Using Arduino with Voice Alert" International Journal of Advance Engineering and Research Development (IJARED), P-ISSN; 2348-6406.

[13] Sarfaraz, N. S., (2015). "Digital Protection of Transformer using Arduino with Voice Alert", International Journal of Innovations in Engineering and Technology (IJIET), Vol. 6, Issue 2.

[14] Electric4u.com. (2018, August 29). https://www.electrical4u.com/magnetizing-inrush-current-inpower-transformer/. Retrieved from www.electric4u.com: https: //www.electrical4u.com/magnetizing-inrush-current-inpower-transformer/.

[15] K.Salunke, (2016).”Transformer protection using microcontroller based relay and monitoring using GSM technology" International engineering research journal (IERJ), Vol. 2 issue 2, page 813-817, 2016, ISSN 2395 -1621. 